\title{
HUBUNGAN DUKUNGAN KELUARGA DENGAN KEMAMPUAN INTERAKSI SOSIAL PADA ANAK RETARDASI MENTAL KELAS 1-6 DISDLB-C SHANTI KOSALA MAS TRIP BEGADUNG NGANJUK
}

\author{
Cucuk Suwandi ${ }^{1}$, Wiwik Novitasari ${ }^{2}$ \\ ${ }^{1}$ Dosen Program Studi Pendidikan Ners Stikes Satria Bhakti Nganjuk \\ ${ }^{2}$ Mahasiswa Program Studi Pendidikan Ners Stikes Satria Bhakti Nganjuk \\ Email:wiwiknovita738@yahoo.com
}

\begin{abstract}
Introduction:Families, especially the elderly, play an important role in creating a pleasant atmosphere and teach the norms in children mental retardation, so that children can develop social interaction skills. The purpose of this study was to determine the relationship of family support with the social interaction ability of mental retardation children in SDLB - C Shanti Kosala Mas Trip Begadung Nganjuk. Methods:Research design was correlation with cross sectional approach. This research was conducted at SDLB - C Shanti Kosala Mas Trip Begadung Nganjuk on 9 april 2018. Population in the study was of all families of students of Mental Retardasi in SDLB-C Shanti Kosala Mas Trip BegadungNganjuk, as many as 47 respondents. Sampling technique used was total sampling, so that the sample counted 47 respondents. Instrument used was questionnaire. The independent variable was family support and the dependent variable was the ability of social interaction. Data analysis using Spearman Rank statistical test with $\alpha=0,05$. Results: The results showed that almost all respondents had good family support, as many as 38 respondents (80.9\%), most of them had enough social interaction ability, as many as 30 respondents $(63,8 \%)$. Spearman Rank test results obtained $p$-value $0,000 \leq \alpha(0,05)$ and $r=0,528$. Conslusions: There is a relationship of family support with the social interaction ability of mental retardation children in SDLB - C Shanti Kosala Mas Trip Begadung Nganjuk.
\end{abstract}

Keywords: Family support, social interaction ability, child mental retardation.

\section{PENDAHULUAN}

Penderita Retardasi Mental mengalami keterlambatan dalam semua proses perkembangannya, salah satunya berupa hambatan perilaku adatif ditandai dengan defisit fungsi adaftif, seperti bidang komunikasi, mengurus dirinya sendiri, home living, ketrampilan interpersonal, ketrampilan akademik, dan kemampuan perkembangan sosial terjadi sebelum usia 18 tahun (Khoiri, 2012). Perkembangan yang terlambat pada anak retardasi mental adalah perkembangan kecerdasan yang tidak tercapai optimal.Kecerdasan merupakan salah satu aspek psikologis yang menpunyai kontribusi cukup besar terhadap stimulasi verbal maupun non verbal, terutama yang memiliki unsur kebahasaan.Masalah yang 
sering terjadi pada anak retardasi mental yaitu anak tidak dapat bergaul atau bermain dengan teman sebayanya karena mengalami kesulitan dalam berkomunikasi (Zahra, 2007). Retardasi mental kurang mampu dalam penyesuaian diri dengan lingkungan, kurang mampu dalam perawatan diri sendiri, kesulitan dalam berbahasa dan komunikasi serta ketrampilan sosial untuk adaptasi dengan orang lain atau berinteraksi sosial, selain itu anak retardasi mental mengalami kesulitan berkomunikasi dengan orang lain dan sulit menyesuaikan diri dengan lingkungan sehingga menyebabkan berperilaku abnormal seperti hiperaktif, kanak-kanak, serta menarik diri. Hasil studi pendahuluan pada tanggal 5 Oktober 2017 wawancara dengan Ibu Surati, S.Pd Selaku Kepala Sekolah SDLB-C Shanti Kosala Mas Trip Begadung Kabupaten Nganjuk mengatakan bahwa anak retardasi mental rata-rata belum mampu melakukan interaksi sosial seperti bergaul dengan teman sebayanya atau berbaur dengan anak-anak lain, sebenarnya anak bisa melakukan interaksi sosial tetapi tergantung dukungan atau pendekatan dengan lingkungan sekitar dan sebagian besar keluarga anak retardasi mental kurang memberikan dukungan keluarga kepada anak-anaknya untuk melakukan interaksi sosial dilingkungan sekitar, sehingga kemandirian dalam berhubungan dilingkungan sekitar masih bergantung pada orang lain.

Retardasi mental merupakan masalah di dunia dengan implikasi yang besar terutama di negara berkembang didapatkan bahwa jumlah penyandang retardasi mental adalah 2,3\%. Data Biro Pusat Statistik (BPS) tahun 2010, dari 222 juta penduduk indonesia, sebanyak $0,7 \%$ atau 2,8 juta jiwa cacat. Populasi anak penderita retardasi mental menepati angka paling besar dibanding dengan jumlah anak dengan keterbatasan lain. Prevelensi retardasi mental di indonesia saat diperkirakan 1-3\% dari penduduk indonesia, sekitar 6,6 juta jiwa. Retardasi Mental 1,5kali lebih banyak pada laki-laki dibanding dengan perempuan (Judarwanto, 2009). Pada tahun 2007 jumlah penyandang cacat di indonesia dari jumlah penduduk yaitu sebesar 211.428.572 atau 1.480 .000 jiwa. Sedangkan diprovinsi jawa timur penderita Retardasi Mental sebanyak 125.190 jiwa.Dari 9 SLB di Kabupaten Nganjuk pada tahun 2017 terdapat 506 penyandang retardasi mental.Sedangkan data di SLDB-C Shanti Kosala Mas Trip Begadung Kabupaten Nganjuk priode 2017/2018 didapatkan total 47 siswa dengan Retardasi Mental.

Kemampuan interaksi sosial anak dapat dipengaruhi oleh sikap atau penerimaan keluarga.Sehingga berpengaruh 
pada kemampuan interaksi sosial anak baik dalam keluarga ataupun masyarakat dalam penyesuaian diri, tingkah laku, sikap pergaulannya dan berusaha hidup mandiri.Ketidaksesuian harapan orang tua dengan potensi yang dimiliki anak cenderung menimbulkan masalah di kemudian hari dalam proses perkembangan anak. Orang tua mencemaskan masa depan anak sebagai salah satu proyeksi kecemasan dirinya dituangkan pada anak. Akibatnya kecemasan orang tua mempengaruhi kecenderungan untuk melindungi anak secara berlebihan, sehingga kemampuan interaksi sosial anak justru semakin dibatasi (Zahra, 2007).Keluarga yang mempunyai anak dengan retardasi mental akan memberikan perlindungan yang berlebihan pada anaknya sehingga anak mendapatkan kesempatan yang terbatas untuk mendapatkan pengalaman yang sesuai dengan tingkat perkembangannya.

Dukungan keluarga dan perhatian khusus terutama dari orang tua sangat dibutuhkan pada perkembangan anak retardasi mental.Perhatian khusus tersebut meliputi membantu anak agar timbul sikap percaya diri, mandiri, menjadi manusia yang produktif, memiliki kehidupan yang layak, aman terlindungi, dan bahagia lahir dan batin (Listyaningsih dan Dewayani, 2010). Keluarga memiliki peranan penting bagi perkembangan anak retardasi mental terutama orang tua yang akan memberikan dasar pendidikan agama, memciptakan suasana yang menyenangkan, serta mengajari tentang norma baik dan buruk yang ada di dalam masyarakat (Ulfatusholiat, 2009). Selain itu, peran tenaga kesehatan dan pendidik di SDLB sangat dibutuhkan dalam memberikan edukasi pada orangtua anaktentang retardasi mental, sehingga orangtua dapat memberikan dukungan yang tepat bagi perkembangan kemampuan interaksi sosial anak.

\section{METODE PENELITIAN}

Desain penelitian ini menggunakan desain korelasi (hubungan) dengan pendekatan cross sectional yaitu dimana peneliti melakukan observasi atau pengukuran variabel satu kali saja dan pengukuran variabel dependen dan independen dilakukan pada saat pemeriksaan atau pengkajian data (Nursalam, 2008). Penelitian ini dilaksanakan pada tanggal 9 april2018 di SLDB-C Shanti Kosala Mas Trip Begadung Kabupaten Nganjuk. Populasi penelitian ini adalah semua keluarga siswa penderita Retardasi Mental di SDLB-C Shanti Kosala Mas Trip, Begadung, Kabupaten Nganjuk.Jumlah populasi sebesar 47 
orang.Sampel dalam penelitian ini diambil dengan teknik total samplingdan diperoleh besar sampel sebanyak 47 responden.Variabel independen penelitian ini ialah dukungan keluarga, sedangkan variabel dependen ialah kemampuan interaksi sosial anak retardasi mental.Instrumen yang digunakan dalam penelitian ini adalah kuesioner.

Analisa data statistik dilakukan dengan uji Spearman Rankdengan $\alpha=0,05$. Adapun pedoman untuk pengujian hipotesis adalah:
1. $\mathrm{H}_{\mathrm{a}}$ diterima jika $\rho$-value $\leq \alpha$ yang berarti bahwa ada hubungan antara dukungan keluarga dengan kemampuan interaksi sosial pada anakretardasi mental diSDLB-C Shanti Kosala Mas Trip Begadung Kabupaten Nganjuk.

2. $\mathrm{H}_{\mathrm{a}}$ ditolak jika $\rho$-value $>\alpha$ yang berarti tidak ada hubungan antara dukungan keluarga dengan kemampuan interaksi sosial pada anakretardasi mental diSDLB-C Shanti Kosala Mas Trip Begadung Kabupaten Nganjuk.

\section{HASIL PENELITIAN}

Tabel 1. Hasil Penelitian Dukungan Keluarga dan Kemampuan Interaksi Sosial pada Anak Retardasi Mental di SDLB-C Shanti Kosala Mas Trip Begadung Kabupaten Nganjuk, Tanggal 9 april 2018.

\begin{tabular}{|c|c|c|c|}
\hline Variabel & Kategori & $f$ & $\%$ \\
\hline \multirow{3}{*}{ Dukungan Keluarga } & Baik & 38 & 80,9 \\
\hline & Cukup & 7 & 14,9 \\
\hline & Kurang & 2 & 4,3 \\
\hline \multicolumn{2}{|l|}{ Jumlah } & 47 & 100 \\
\hline \multirow{3}{*}{$\begin{array}{c}\text { Kemampuan Interaksi Sosial pada } \\
\text { Anak Retardasi Mental }\end{array}$} & Baik & 11 & 23,4 \\
\hline & Cukup & 30 & 63,8 \\
\hline & Kurang & 6 & 12,8 \\
\hline \multicolumn{2}{|l|}{ Jumlah } & 47 & 100 \\
\hline
\end{tabular}

Hasil penelitian ini menunjukkan bahwa dari 47 responden, hampir seluruhnya memiliki dukungan keluarga yang baik, yaitu sebanyak 38 responden (80,9\%). Diketahui pula dari 47 responden, sebagian besar memiliki kemampuan interaksi sosial cukup, yaitu sebanyak 30 responden $(63,8 \%)$. 
Tabel 2. Tabulasi SilangDukungan Keluarga dengan Kemampuan Interaksi Sosial pada Anak Retardasi Mental di SDLB-C Shanti Kosala Mas Trip Begadung Kabupaten NganjukTanggal 9 april 2018.

\begin{tabular}{|c|c|c|c|c|c|c|c|c|}
\hline \multirow{3}{*}{ Dukungan Keluarga } & \multicolumn{6}{|c|}{ Kemampuan Interaksi Sosial } & \multirow{2}{*}{\multicolumn{2}{|c|}{ Jumlah }} \\
\hline & \multicolumn{2}{|c|}{ Baik } & \multicolumn{2}{|c|}{ Cukup } & \multicolumn{2}{|c|}{ Kurang } & & \\
\hline & $\mathrm{Jml}$ & $\%$ & $\mathrm{Jml}$ & $\%$ & $\mathrm{Jml}$ & $\%$ & $\mathrm{Jml}$ & $\%$ \\
\hline Baik & 10 & 21,3 & 28 & 59,6 & 0 & 0 & 38 & 80,9 \\
\hline Cukup & 1 & 2,1 & 2 & 4,3 & 4 & 8,5 & 7 & 14,9 \\
\hline Kurang & 0 & 0 & 0 & 0 & 2 & 4,3 & 2 & 4,3 \\
\hline Total & 11 & 23,4 & 30 & 63,8 & 6 & 13 & 47 & 100 \\
\hline$p$-value $=0,000$ & $05 \mathrm{r}=$ & & & & & & & \\
\hline
\end{tabular}

Tabulasi silang menunjukkan bahwa dari 47 responden, sebagian besar memiliki dukungan keluarga baik dengan kemampuan interaksi sosial anak cukup, yaitu sebanyak 28 responden (59,6\%). Selanjutnya hasil uji Spearman Rankmenunjukkan $p$-value $=0,000 \leq \alpha$ $(0,05)$ sehingga Ha diterima artinya ada hubungan dukungan keluarga dengan kampampuan interaksi sosial pada anak retardasi mental kelas1-6di SDLB-C Shanti KosalaMas Trip Begadung Nganjuk.Nilai $\mathrm{r}$ diperoleh sebesar 0,528 menunjukkan keeratan hubungan yang sedang dan arah hubungan bersifat positif atau searah, artinya semakin baik dukungan keluarga, maka kemampuan interaksi sosial responden juga semakin baik.Demikian pula berlaku sebaliknya, semakin kurang dukungan keluarga, maka semakin kurang pula kemampuan interaksi sosial responden.

\section{PEMBAHASAN}

\section{Dukungan Keluarga Anak Retardasi}

\section{Mental}

Hasil penelitian menunjukkan

pendidikan SMA. Hasil uji bahwa dari 47 responden, hampir seluruhnya memiliki dukungan keluarga yang baik, yaitu sebanyak 38 responden (80,9\%). Dari 38 responden yang memiliki dukungan keluarga baik, sebagian besar yaitu 21 responden $(55,3 \%)$ memilikiumur 40-49 tahundan sebagian besar yaitu20 responden $(52,6 \%)$ memiliki statistikdidapatkan $p$-valueumur orang tua $=$ 0,037dan $p$-value pendidikanorang tua $=$ 0,000, sehingga dukungan keluarga dipengaruhi oleh umur dan pendidikan orang tua.

Menurut Setiadi (2008), umur orang tua khususnya ibu dapat mempengaruhi pemberian perhatian kepada anak. Ibu 
yang memiliki usia dewasa cenderung lebih mampu merasakan atau mengenali kebutuhan anaknya dibanding dengan usia ibu yang lebih muda.Hal ini berlaku tidak hanya pada anak normal tetapi juga pada anak retardasi mental yang justru lebih membutuhkan perhatian dari orang tua.Listyaningsih (2010) menyatakan bahwa tingkat pendidikan orang tua merupakan faktor yang penting dalam mendukung proses tumbuh kembang anak, karena dengan pendidikan yang baik maka orang tua dapat menerima informasi yang datang dari luar terutama dengan cara pengasuhan anak yang baik agar anak dapat menjadi sehat dan dapat tumbuh dan berkembang sebagaimana mestinya. Dari pernyataan tersebut dapat diasumsikan bahwa semakin tinggi tingkat pendidikan orang tua, maka kesadarannya untuk memberikan dukungankesehatan terhadap anaknya akan semakin besar.

Peneliti beropini bahwa dukungan keluarga anak retardasi mental di SDLB-C Shanti KosalaMas Trip Begadung Nganjuk hampir seluruhnya baik, karena dipengaruhi oleh umur keluarga atau orang tua yang hampir setengahnya berusia 40-49 tahun. Pada umur tersebut, keluarga telah memiliki cukup pengalaman hidup, matang dalam berpikir dan mampu mengembangkan sikap sabar dan ikhlas dalam memberikan dukungan bagi anaknya yang mengalami retardasi mental. Disamping itu, tingkat pendidikan keluarga atau orang tua yang hampir setengahnya adalah SMA, dimana pada tingkat pendidikan tersebut, keluarga memiliki pengetahuan yang baik tentang pentingnya memberikan dukungan bagia anak retardasi mental agar dapat bertumbuh kembang dengan lebih baik di masyarakat

\section{Kemampuan Interaksi Sosial Anak Retardasi Mental}

Hasil penelitian menunjukkan bahwa dari 47 responden, sebagian besar memiliki kemampuan interaksi sosial cukup, yaitu sebanyak 30 responden $(63,8 \%)$. Dari 30 responden yang memiliki kemampuan interaksi sosial cukup, hampir setengahnya yaitu 14 responden (46,7\%) memilikipendidikan SMAdan sebagian besar yaitu16 responden $(53,3 \%)$ memiliki pekerjaan sebagai ibu rumah tangga. Hasil uji statistikdidapatkan $p$-valuependidikan $=$ 0,000dan $p$-valuepekerjaan $=0,000$, sehingga kemampuan interaksi sosial anak retardasi mental dipengaruhi oleh pendidikan dan pekerjaan orang tua.

Menurut Soekanto (2012), proses pembentukan kemampuan interaksi sosial pada anak dipengaruhi oleh tingkat pengetahuan orang tuanya, khusunya ibu. Tingkat pengetahuan tersebut sangat 
ditentukan oleh tingkat pendidikan ibu, karena semakin tinggi pendidikan ibu, maka semakin baik pengetahuannya tentang pola asuh pada anak retardasi mental. Sementara menurut Soetjiningsih (2013), ibu rumah tangga atau ibu yang tidak bekerja akan punya banyak waktu dalam memperhatikan kebutuhan anaknya dan memberikan tindakan stimulasi yang optimal, baik pada anak normal maupun anak retardasi mental. Sebaliknya ibu yang sibukbekerja pada umumnya tidak punya banyak waktu untuk memperhatikan kebutuhan anaknya, termasuk dalam pemberian tindakan stimulasi tumbuh kembang mereka.Dengan demikian ibu rumah tangga memiliki peran yang lebih besar dan optimal dalam memberikan stimulasi kemampuan interaksi sosial pada anak retardasi mental daripada ibu yang aktif bekerja.

Peneliti beropini bahwa sebagian besar responden anak retardasi mental di SDLB-C Shanti KosalaMas Trip Begadung Nganjuk memiliki kemampuan interaksi sosial yang cukup disebabkan karena tingkat pendidikan ibu sudah cukup tinggi, yaitu SMA, sehingga mereka memiliki pengetahuan yang cukup baik tentang cara memberikan stimulasi pada anak retardasi mental agar mereka memiliki kemampuan interaksi sosial yang baik sesuai kebutuhannya. Selain itu, ibu rumah tangga atau ibu yang tidak bekerja dapat menjalankan peran stimulasi secara lebih optimal, karena memiliki lebih banyak waktu kebersamaan dengan anak retardasi mental.

\section{Hubungan Dukungan keluarga dengan Kemampuan Interaksi Sosial Anak Retardasi Mental}

Hasil penelitian pada Tabel 4.3 menunjukkan bahwa dari total 47 responden, diketahui bahwa sebagian besar memiliki dukungan keluarga baik dengan kemampuan interaksi sosial anak cukup, yaitu sebanyak 28 responden (59,6\%). Hasil uji Spearman Rankmenunjukkan $p$-value $=0,000 \leq \alpha$ $(0,05)$ sehingga Ha diterima artinya ada hubungan dukungan keluarga dengan kampampuan interaksi sosial pada anak retardasi mental kelas1-6di SDLB-C Shanti KosalaMas Trip Begadung Nganjuk.Nilai r diperoleh sebesar 0,528 menunjukkan keeratan hubungan yang sedang dan arah hubungan bersifat positif atau searah, artinya semakin baik dukungan keluarga, maka kemampuan interaksi sosial responden juga semakin baik.

Menurut Goshali (dalam Irmawati, 2017), anak retardasi mental mengalami kesulitan dalam berinteraksi sosial dengan 
orang lain, karena keterbatasan intelektual dan penyesuaian diri, namun faktor lingkungan juga mempengaruhi cara anak retardasi mental dalam melakukan interaksi sosial. Lingkungan tersebut tidak hanya lingkungan sekolah, tetapi juga lingkungan keluarga yang memegang peran penting dalam memberikan dukungan pada anak (Rosnawati, 2013).Hasil penelitian ini mendukung penelitian terdahulu yang dilakukan Ulfatusholiat (2009) yang menyatakan bahwa dukungan keluarga memiliki hubungan dengantumbuh kembang anak retardasi mental, khususnya peran orang tua dalam memberikan nilai moral, menciptakan suasana yang menyenangkan, dan mengajari anak cara berkomunikasi dengan orang-orang di sekitarnya.

Berdasarkan uraian fakta dan teori di atas, maka peneliti beropini bahwa dukungan keluarga atau orang tua merupakan faktor penting yang mempengaruhi kemampuan interaksi sosial anak retardasi mental di SDLB-C Shanti KosalaMas Trip Begadung Nganjuk.Keluarga harus berperan aktif untuk terus mendukung anak agar semakin mampu berinteraksi dengan orang lain. Agar dukungan keluarga lebih berjalan lebih optimal, maka diperlukan kerjasama dengan guru di sekolah untuk menerapkan metode-metode stimulasi yang tepat diterapkan di rumah dan memonitor tingkat perkembangan kemampuan interaksi sosial anak secara berkelanjutan

\section{KESIMPULAN}

Berdasarkan hasil penelitian dan pembahasan, maka dapat disimpulkan bahwahampir seluruh responden memiliki dukungan keluarga yang baik, yaitu sebanyak 38 responden (80,9\%). Sebagian besar responden memiliki kemampuan interaksi sosial cukup, yaitu sebanyak 30 responden (63,8\%). Ada hubungan antara dukungan keluarga dengan kemampuan interaksi sosial pada anak retardasi mental kelas 1-6 di SDLB-C Shanti Kosala Mas Trip Begadung Nganjuk. Hal ini dibuktikan dari hasil uji Spearman Rank menunjukkan $p$-value $=0,000<\square(0,05)$ sehingga Ha diterima. Sedangkan nilai $r$ diperoleh sebesar 0,528 menunjukkan keeratan hubungan yang sedang dan arah hubungan bersifat positif atau searah, artinya semakin baik dukungan keluarga maka kemampuan interaksi sosial anak juga semakin baik.Saran yang diberikan bagi perawat agar memberi informasi kepada pihaksekolah dan orangtua anak tentang pentingnya peranan orang tua dalamperkembangan sosial anak retardasi mental sehingga dapat dijadikan acuan 
dalam memberikan asuhan keperawatan pada keluarga anak retardasi mental, perawat, pendidikan kesehatan, maupun konseling keluarga. Disarankan pada orang tua anakagar terbuka dan menambah wawasan tentang retardasi mental, karena dengan lebih terbuka dan berkomunikasi dengan konselor atau perawat dapat meringankan beban orang tua yang memiliki anak retardasi mental.

\section{DAFTAR PUSTAKA}

Arikunto, S. (2006). Prosedur Penelitian. Jakarta: Rineka Cipta.

Dinas Kesehatan Republik Indonesia. 2010. Pedoman Pelayanan Kesehatan Di Sekolah Luar Biasa. Www.Gizikia. Depkes .Go.Id. Diakses tanggal 30 oktober 2017 Jam 14.00 WIB.

Irmawati. 2017. Hubungan Antara Dukungan Keluarga Dengan Kemampuan Sosialisasi Anak Retardasi Mental Usia Sekolah Di SLB Ngeri Semarang. http://respository.unissula.ac.id/id/e prir. Diakses Tanggal 17 Oktober 2017 Jam 14.00 WIB.

Judarwanto. 2009. Retardasi Mental: Pencegahan dan Penanganan. Http://koranindonesiasehat.jurnal. Diakses pada tanggal 16 Okotober 2017 jam 18.30 WIB.

Khoiri, H. 2012. Penerimaan Orang Tua Terhadap Anak Retardasi Mental Ditinjau Dari Kelas. Jurusan Psikologi. Fakultas Ilmu Pendidikan
Univervitas Negeri Semarang:

Indonesia.

Http://Journal/Unnes.Ac.Id/

Sju/Index.Php/Dcp. Diakses 18

Okterber 2017 Jam 18.00 WIB.

Listyaningsih, R. \& Dewayani, $\mathrm{T}$. 2010.Kepercayaan Diri Orang Tua Yang Memiliki Anak Tunagrahita. Fakultas Psikologi Universitas Mercu Buana: Yogyakarta.

Notoatmodjo, S. 2012. Metologi Penelitian Kesehatan. Jakarta: Rineka Cipta.

Nursalam. 2016. Metodologi Penelitian Iimu Keperawatan. Jakarta: Salemba

Rosnawati, Kemis. (2013). Pendidikan Anak Berkebutuhan Khusus Tunagrahita. Jakarta Timur: Luxima.

Setiadi. 2008. Konsep \& Proses Keperawatan Keluarga.Yogyakarta: Graha Ilmu.

Soekanto, Soejono. 2012. Sosiologi Suatu Pengantar. Https://jurnal.ugm.ac.id/ populasi/article/viewFile/ Diakses tanggal 4 Oktober 2017. Jam 12.00 Wib.

Soetjiningsih. 2013. Tumbuh Kembang Anak, Ed. 2. Jakarta: ECG.

Ulfatusholiat, R. Peran Orang Tua Dalam Penyesuaian Diri Anak Tunagrahita.Universitas gunadarma.http://www.gunadarma.a c.id/. Diakses pada 30 Oktober 2017 Jam 22: 00 WIB.

Zahra.2007. Harapan Tak Realistik Dari Orang Tua Penyandang Retardasi Mental (Sebuah Studi Kasus).Jurnal Provitae.Volume 3.1 Mei 2007. 